OPEN ACCESS

Edited by:

Mothaffar Rimawi,

Baylor College of Medicine,

United States

Reviewed by:

Tomás Pascual Martinez, Hospital Clínic of Barcelona, Spain

Masahiko Tanabe,

The University of Tokyo, Japan

${ }^{*}$ Correspondence:

Weiguang Liu

Iwg1943@163.com

Bo Chen

chbyx1@163.com

Specialty section: This article was submitted to

Women's Cancer,

a section of the journal

Frontiers in Oncology

Received: 28 March 2019 Accepted: 24 June 2019

Published: 09 July 2019

Citation:

Liu W, Chen G, Sun L, Zhang Y, Han J, Dai Y, He J, Shi S and Chen B

(2019) TUFT1 Promotes Triple Negative Breast Cancer Metastasis, Stemness, and Chemoresistance by

Up-Regulating the Rac1/ $\beta$-Catenin Pathway. Front. Oncol. 9:617.

doi: 10.3389/fonc.2019.00617

\section{TUFT1 Promotes Triple Negative Breast Cancer Metastasis, Stemness, and Chemoresistance by Up-Regulating the Rac1/ $\beta$-Catenin Pathway}

\author{
Weiguang Liu ${ }^{1 *}$, Guanglei Chen ${ }^{2}$, Lisha Sun ${ }^{2}$, Yue Zhang ${ }^{3}$, Jianjun Han ${ }^{1}$, Yuna Dai ${ }^{1}$, \\ Jianchao He ${ }^{1}$, Sufang Shi ${ }^{1}$ and Bo Chen ${ }^{4 *}$
}

${ }^{1}$ Department of Breast Surgery, Affiliated Hospital of Hebei University of Engineering, Handan, China, ${ }^{2}$ Department of Breast Surgery, Shengjing Hospital of China Medical University, Shenyang, China, ${ }^{3}$ Department of Physiology, Dalian Medical University, Dalian, China, ${ }^{4}$ Department of Breast Surgery, The First Hospital of China Medical University, Shenyang, China

Objectives: Triple negative breast cancer (TNBC) is a subtype of breast cancer with stronger invasion and metastasis, but its specific mechanism of action is still unclear. Tuft1 plays an important regulatory role in the survival of breast cancer cells; however, its role in regulating TNBC metastatic potential has not been well-characterized. Our aim was therefore to systematically study the mechanism of TUFT1 in the metastasis, stemness, and chemoresistance of TNBC and provide new predictors and targets for $\mathrm{BC}$ treatment.

Methods: We used western blotting and IHC to measure TUFT1and Rac1-GTP expression levels in both human $\mathrm{BC}$ samples and cell lines. A combination of shRNA, migration/invasion assays, sphere formation assay, apoptosis assays, nude mouse xenograft tumor model, and GTP activity assays was used for further mechanistic studies.

Results: We demonstrated that silencing TUFT1 in TNBC cells significantly inhibited cell metastasis and stemness in vitro. A nude mouse xenograft tumor model revealed that TUFT1 knockdown greatly decreased spontaneous lung metastasis of TNBC tumors. Mechanism studies showed that TUFT1 promoted tumor cell metastasis and stemness by up-regulating the Rac $1 / \beta$-catenin pathway. Moreover, mechanistic studies indicated that the lack of TUFT1 expression in TNBC cells conferred more sensitive to chemotherapy and increased cell apoptosis via down-regulating the Rac1/ $\beta$-catenin signaling pathway. Further, TUFT1 expression positively correlated with Rac1-GTP in TNBC samples, and co-expression of TUFT1 and Rac1-GTP predicted poor prognosis in TNBC patients who treated with chemotherapy.

Conclusion: Our findings suggest that TUFT1/Rac $1 / \beta$-catenin pathway may provide $a$ potential target for more effective treatment of TNBC.

Keywords: triple negative breast cancer (TNBC), TUFT1, Rac1, metastasis, stemness, chemoresistance 


\section{INTRODUCTION}

Triple negative breast cancer (TNBC) is a subtype of BC that lacks estrogen or progesterone receptors and has no epidermal growth factor receptor 2 amplification, accounting for about $20 \%$ of the total breast cancer (1-3). TNBC is defined mainly based on its pathology. Its features overlap with those of basal-like $\mathrm{BC}$, one of five subgroups based on microarray gene expression profiling $(4,5)$. TNBC usually presents with less favorable clinical features than other subtypes of breast cancer, for example, tumors proliferate faster, relapse earlier and metastasis more easily and is usually associated with poorer prognosis as a result (6-8). However, the mechanism by which TNBC's metastasis is less clear. In addition, there are currently no very effective targeted drugs available for TNBC, cytotoxic chemotherapy remains the main adjuvant therapy for this subtype of breast cancer (9). A more in-depth study of the mechanism of TNBC metastasis may be able to more efficiently find its target, and at the same time provide theoretical support for the exploration of new TNBC therapeutic drugs.

Tuftelin (TUFT1) is an acidic, hydrophilic, glycosylated, and phosphorylated protein. Sequence and characterization analysis has shown that TUFT1 is well conserved, with high homology across various species. The protein is considered to act on enamel mineralization and is involved in the interaction between mesenchymal ectoderm and autosomal enamel dysplasia during tooth development (10). Zhou et al. (11) demonstrated that the expression of TUFT1 protein in pancreatic cancer is higher than that in normal pancreatic tissue. Its expression is closely related to both the disease stage and local lymph node metastasis. Cell function experiments further confirmed that TUFT1 depletion reduced proliferation and metastasis of pancreatic cancer cells, and impaired various proteins expression related to epithelialmesenchymal transition. The authors suggested that TUFT1 may affect HIF1 by influencing the expression of members of the Snail signaling pathway, which regulates epithelial mesenchymal transition. Our previous study found that inhibition of TUFT1 expression in breast cancer cells inhibited proliferation, affected the cell cycle, and induced apoptosis. In addition, we showed that suppression of TUFT1 affected the expression of the proteins RelA, Caspase 3, DUSP1, and Rac1 $(12,13)$. Kawasak et al. (14) found that TUFT1 activated the mTORC1 signaling pathway by regulating the Rab GTPase, and that the interaction between TUFT1 and RabGAP1 mediated intracellular lysosome localization and vesicle transport in tumor cells. However, the precise role of TUFT1 in breast cancer (BC), including the mechanics of TNBC's metastasis remain unclear.

Rac1 is a member of the Rho GTPases family, which is a subgroup of the Ras superfamily (15). Rac1 is activated by binding to GTP, while it is deactivated by binding to GDP, which makes it play an important role in many signaling pathways (16). Rac1 plays an important role in cancer progression (17), affecting cell adhesion, proliferation, migration, invasion, and cancer metastasis (18-20). The new study highlights the importance of Rac1 activation in cancer metastasis and acquired chemoresistance (21-24). One major mechanism by which Rac1 may provide resistance to chemotherapy is its role in apoptosis regulation. Rac1-GTP can bind directly to the key apoptotic regulator Bcl-2 to elicit anti-apoptotic cell responses (25). Many studies have also proved that Racl-GTP can affect the genes Nanog, Sox2, and Oct4, which play a central regulatory role in CSC (26-28). Rao et al. (29) showed that Rac1/ $\beta$-catenin pathway participated in SEMA3F-mediated regulation of colorectal cancer cell stemness. In addition, Kawasak et al. (14) found that TUFT1 increased Racl levels through activation of the AKT/mTOR pathway. However, the functional mechanism of TUFT1 in metastasis, stemness, and chemoresistance of BC, especially in TNBC, has not been adequately characterized.

In this study, we showed that stable TUFT1 knockdown in TNBC cells drastically inhibited their migration, invasiveness, and CSC-like properties. Moreover, we found that the expression of TUFT1 increased significantly in TNBC samples. The coexpression of TUFT1 and Rac1-GTP suggested poor prognosis. Further functional studies showed that TUFT1 promoted TNBC cell metastasis, stemness, and chemoresistance by up-regulating the $\mathrm{Rac} 1 / \beta$-catenin signaling pathway.

\section{MATERIALS AND METHODS}

\section{Human Specimens}

In our study, we recruited 60 pathologically confirmed TNBC patients at Affiliated Hospital of Hebei University of Engineering, between January 2014 and December 2014. All patients treated with anthracycline followed by taxanes chemotherapy after surgery. This study was carried out in accordance with the recommendations of ICMJE with written informed consent from all subjects. All subjects gave written informed consent in accordance with the Declaration of Helsinki. The protocol was approved by the Ethics Committee of Affiliated Hospital of Hebei Engineering University.

\section{Human BC Cell Lines and Plasmids}

HCC1937 cell line was obtained from the American Type Culture Collection (USA). MDA-MB-231 cell line was gained from the Chinese Academy of Sciences (China). Cells were cultured in RPMI-1,640 mixed with 10\% FCS in an atmosphere containing $5 \% \quad \mathrm{CO}_{2}$. Recombinant retroviruses carrying PLNCX2-vector or PLNCX2-TUFT1 were synthesized based on relevant instructions (Clontech). MDA-MB-231 or HCC1937 cells with Polybrene $[8 \mu \mathrm{g} / \mathrm{mL}$ (Sigma-Aldrich)] were infected these retroviruses and then were selectively isolated with G418 [750 $\mathrm{g} / \mathrm{mL}$ (Calbiochem)].

\section{RNA Interference}

The recombinant adenoviruses encoding 2 different shorthairpin RNAs (shRNAs), respectively specific for human TUFT1 were designed and prepared from company (GeneChem, Shanghai, China).TUFT1-shRNA\#1: AGAGAATTTAGAGATG CAT; TUFT1-shRNA\#2: GGTGGAGTATTTACGGTAAAC. Lentiviruses were transfected into cells based on the relevant instructions. The ability of TUFT1 knockdown was assessed by real-time quantitative PCR and western bolt. Cell lines with over $80 \%$ efficacy were considered stable. More than $80 \%$ of the cell transfection efficiency was considered stable. 


\section{IHC Analyses}

TUFT1 (dilution 1:100, Abcam, USA), RAC1-GTP (dilution 1:800, NewEast Bioscience, USA), were purchased. The experimental method was carried out and the expression of TUFT1 and RAC1-GTP was evaluated semi-quantitatively according to the criteria described previously $(12,13)$. The analysis was performed by two independent pathologists.

\section{Real-Time PCR}

Total RNA was extracted by Trizol (Invitrogen) for reverse transcription, according to manufacturer's instructions (Invitrogen). TUFT1 expression was examined by Real-time PCR according to the criteria described previously $(12,13)$.

\section{Western Blot}

The rabbit antibodies used to detect TUFT1, Rac1, $\beta$ catenin, Nanog, SOX2, and OCT4 were obtained from AbCam (Cambridge, UK). Their protein levels were examined by western blot according to the criteria described previously $(12,13)$.

\section{Wound Healing Assay}

Following the manufacturer's recommendations, marker pen was used on the back of the 6-well plate, horizontal lines were evenly drawn, about $2 \times 10^{5}$ cells were added, and the next day, the gun head was scratched. Cells were washed with PBS for 3 times and serum-free medium was added. Incubate in a $37^{\circ} \mathrm{C}, 5 \% \mathrm{CO} 2$ incubator. Sample at $0,8,24 \mathrm{~h}$ and take photos.

\section{Invasion Assay}

The required number of chambers were placed in a new 24-well plate and $500 \mu \mathrm{L}$ serum-free medium was added to the upper and lower chambers, respectively. The preparation of serum-free cell suspension is usually $5 \times 10^{4}$ cells/well (24-well plate). $500 \mu \mathrm{L}$ cell suspension was added to the upper chamber and $750 \mu \mathrm{L} 30 \%$ FBS medium was added to the lower chamber. The incubator was incubated at $37^{\circ} \mathrm{C}$ for $24 \mathrm{~h}$. Hematoxylin and eosin (H\&E) stained cells to the lower surface of the membrane. Photographs are taken under a microscope.

\section{Transwell Assay}

Serum-free cell suspension was prepared and counted, usually $5 \times 10^{4}$ cells/well (24-well plate). Carefully remove the culture medium in the upper chamber and add $100 \mu \mathrm{L}$ cell suspension. Add $600 \mu \mathrm{L}$ 30\% FBS culture medium in the lower chamber. The incubator was incubated at $37^{\circ} \mathrm{C}$ for $24 \mathrm{~h}$. The chamber was fixed in $4 \%$ paraformaldehyde for half an hour. 1-2 drops of staining solution were used to stain and transfer cells to the lower surface of the membrane for 1-3 min. Photographs are taken under a microscope.

\section{Sphere Formation Assay}

Cell trypsin of each experimental group in the logarithmic growth phase was digested, serum-free medium was resuspended, cell suspensions were made, and counted. The cell suspension was inoculated in the ultra-low adhesion 6-well plate culture plate at a density of 10,000-20,000 cells/wells, and $2 \mathrm{~mL}$ serum-free medium DMEM/F12 was added to each well. Will the good cells in under the condition of $37^{\circ} \mathrm{C}$ and $5 \% \mathrm{CO} 2$, every 2-3 days in liquid, extend the every 6-8 days. Observe cell balling and morphology under microscope at any time.

\section{Apoptosis Assay}

After infection, supernatant was collected from cell culture in each experimental group in a $5 \mathrm{ml}$ centrifuge tube. The cells were washed once by D-Hanks, the cells were digested by trypsin, and the culture supernatant was terminated. The cells were collected in the same $5 \mathrm{ml}$ centrifuge tube. Centrifuge 1,500 rpm for $5 \mathrm{~min}$ and discard the supernatant. The cells were washed with PBS and precipitated once, centrifuged at 1,500 $\mathrm{rpm}$ for $5 \mathrm{~min}$, and the cells were collected. The cells were washed with $1 \times$ binding buffer for once, centrifuged at 1,500 rpm for $5 \mathrm{~min}$, and the cells were collected. Cell suspension of $100 \mu \mathrm{l}\left(1 \times 10^{5}-1 \times 10^{6}\right.$ cells $)$ was taken and stained with PI complex dyeing liquor $(0.5 \mathrm{~mL})$ for $10-15 \mathrm{~min}$ at room temperature. Flow cytometry was used for detection.

\section{Rac1-GTP Pull-Down Assay}

Cells were splitting in buffer including $25 \mathrm{mM}$ HEPES, $1 \%$ NP40, 10\% glycerin, $5 \mathrm{mM} \mathrm{MgCl2,} 1 \mathrm{mM}$ DTT, $100 \mathrm{mM} \mathrm{NaCl}$, and protease inhibitors. The pyrolysate was cultured on ice for $5 \mathrm{~min}$ and centrifuged for $1 \mathrm{~min}$ with $10,000 \times$ g. Post-nuclear supernatant was tested for pull-down analysis of $30 \mu \mathrm{g}$ GSTRBD (Rac1) pre-coated GSH beads in each case. The beads and supernatant were cultured in a table at $4{ }^{\circ} \mathrm{C}$ for $15 \mathrm{~min}$. The beads were washed with a solution buffer containing $0.01 \%$ NP40, boiled with SDS PAGE, and separated. The beads were analyzed by Western blotting as shown above. NSC23766 (obtained from Tocris Bioscience) was used to inhibit Rac1 activation.

\section{Tumor Metastasis and Growth in Nude Mice}

4-6-weeks female nude mice were obstained from the Shanghai Lingchang Biological Technology Ltd (Shanghai, China). The caudal vein was selectively injected into ShTUFT1-MDA-MB231 cells. The nude mice were anesthetized by isoflurane gas using in vivo imaging instrument with gas anesthesia system. The mice were sacrificed at 10 weeks after treatment, and metastatic lung nodules were counted.

For the in vivo chemoresistance experiment, shTUFT1MDA-MB-231 cells were injected into the flanks of nude mice (10 mice/group). Each group was divide randomly into two subgroups after 2 weeks that were either left untreated or received intraperitoneal injections of doxorubicin $\left(4 \mathrm{mg} \mathrm{kg}^{-1}\right)$ every 5 days(three cycles), as previously described by Ghebeh et al. (30). Animal handling and research protocols were approved by the Ethics Committee of Affiliated Hospital of Hebei Engineering University.

\section{ONCOMINE Analysis}

The mRNA levels of TUFT1 in BCs were determined through analysis of data from the ONCOMINE database (www.oncomine. org). In our study, BC specimen data were compared with control datasets using student's $t$-test to examined the $p$-value. The fold change was defined as 2 , and the $p$-value was set up at 0.01 . 
A

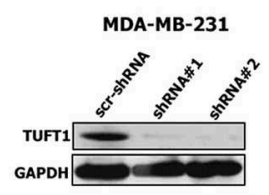

B

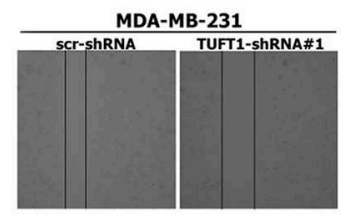

C
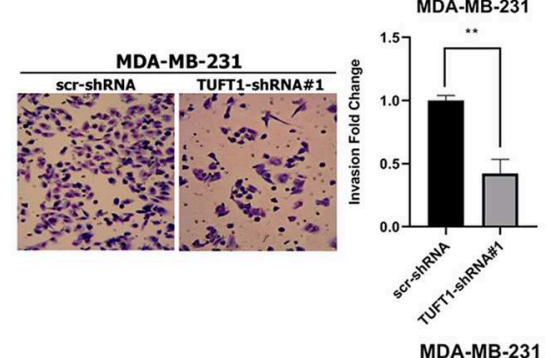

D
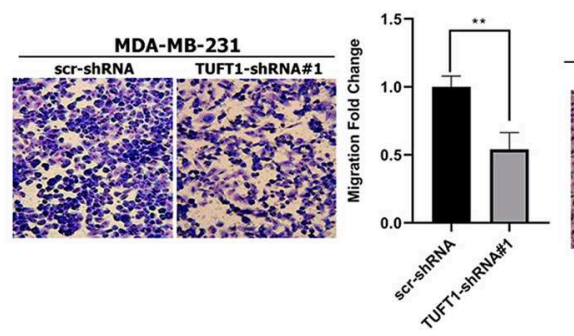

E
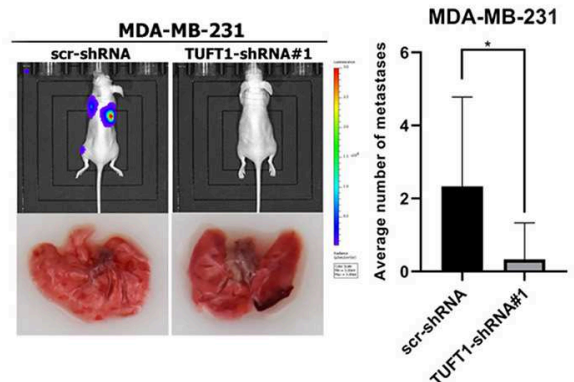

G

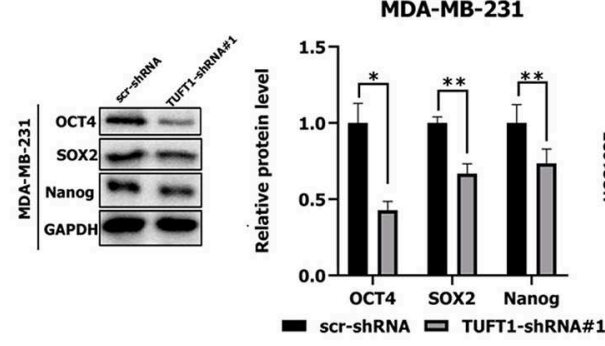

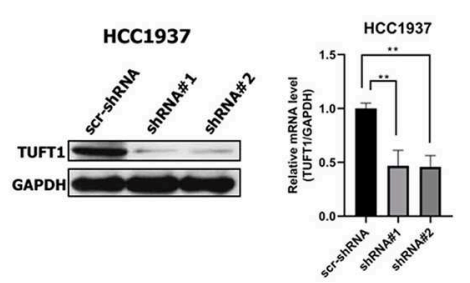
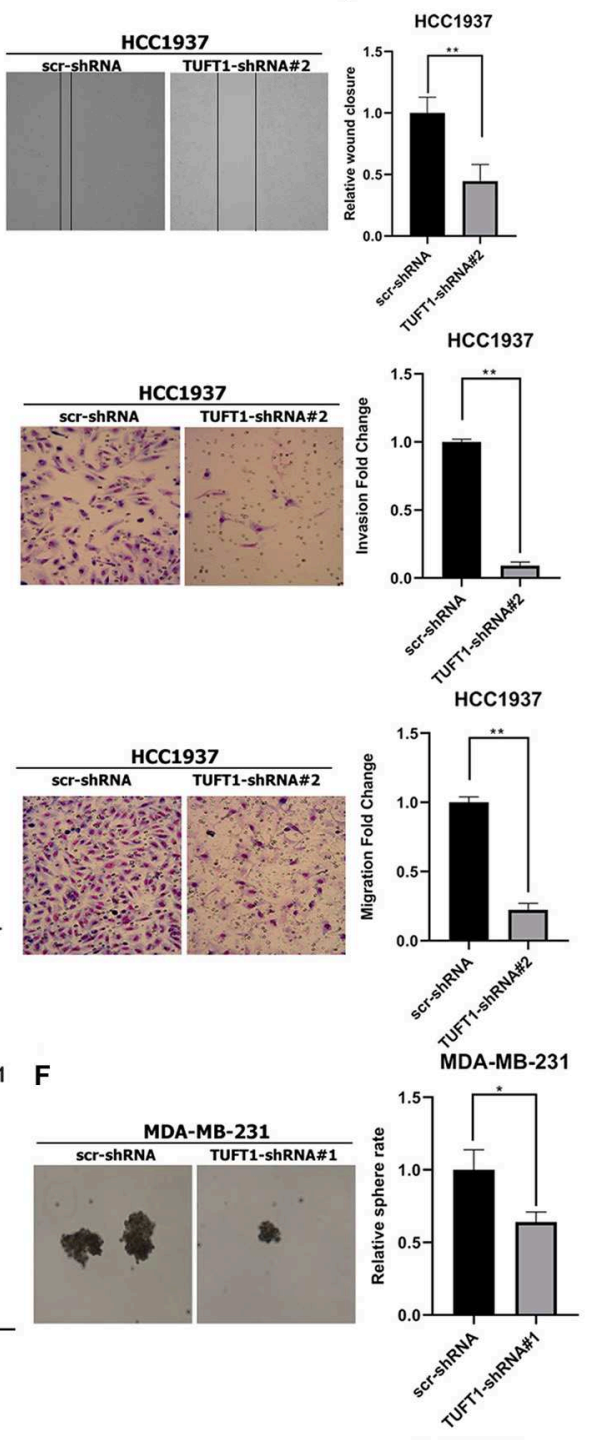

HCC1937

FIGURE 1 | Effects of TUFT1 on migration, invasiveness and stemness in vivo and in vitro. MDA-MB-231 and HCC1937 cells were infected with TUFT1-shRNA or scramble (scr)-shRNA. (A) TUFT1 protein and mRNA expression levels were reduced in MDA-MB-231 and HCC1937 cells with infection of adenovirus encoding 
FIGURE 1 | TUFT1-shRNA\#1 and TUFT1-shRNA\#2. Cell wound (B), invasiveness (C) and migration (D) were aberrant regulated after TUFT1 down-regulation in MDA-MB-231 or HCC1937 cells $(n=3)$. (E) TUFT1 knockdown in MDA-MB-231 cells significantly reduced the number of lung metastatic nodules $(n=10)$. (F) TUFT1 knockdown drastically reduced the number of mammary spheres formed by MDA-MB-231 cells $(n=3)$. (G) The protein levels of Nanog, Sox2 and Oct4 were decreased by TUFT1 knockdown in both MDA-MB-231 and HCC1937 cells $(n=3)$. Results are presented as means \pm SD. The statistical significance was assessed by student's $t$-test; ${ }^{*} p<0.05,{ }^{*} p<0.01$.

\section{Statistical Analysis}

The SPSS 23.0 software was used for statistical analyses. Student's $t$-test and Pearson correlation test were used to compare the classified variables. $p<0.05$ was considered significant.

\section{RESULTS}

\section{TUFT1 Regulates Metastasis and} Stemness of TNBC Cells in vitro and in vivo First, we performed TUFT1 knockdown in the HCC1937 and MDA-MB-231 TNBC cell lines using shRNA. Western blot and Real-time PCR revealed that TUFT1 protein and mRNA levels were prominently reduced in TUFT1-knockdown cells compared to control cells $(p<0.01$, Figure 1A). Wound healing assays, invasion assays, and transwell assays were all used to examined the role of TUFT1 on the migration of TNBC cells. We found that TUFT1 down-regulation markedly reduced the migration of both TNBC cells compared to control cells, indicating that TUFT1 knockdown inhibits cell migratory ability $(p<0.05$, Figures 1B-D).

To expand on our study in vitro, we next examined if TUFT1 could promote the metastasis in TNBC cells. ShTUFT1- MDAMB-231 cells were injected into the caudal vein of nude mice. Then mice were sacrificed for quantitative analysis of lung metastatic nodules. Mice injected with ShTUFT1- MDA-MB231 cells developed significantly fewer metastatic lung nodules than control mice ( $p<0.05$, Figure 1E). Taken together, results in vitro and in vivo reveal the metastatic potential of TUFT1 in TNBC cells.

CSCs play a key role in cancer metastasis $(31,32)$. We used a sphere formation assay to examined the role of TUFT1 on the stemness of TNBC cells. We found that TUFT1 knockdown drastically reduced the number of mammary spheres formed by MDA-MB-231 cells ( $p<0.05$, Figure 1F). Nanog, Sox 2 , and Oct4 play a central regulatory role in CSCs $(26-28,33,34)$. We found that the Nanog, Sox 2 and Oct4 levels were reduced by TUFT1 knockdown in both MDA-MB-231 and HCC1937 cells $(p<0.05$, Figure 1G). These results reveal that TUFT1 is capable of significantly promoting CSC-like properties in TNBC cells.

\section{TUFT1 Promotes the Metastasis of TNBC Cells by Up-Regulating the Rac1/ $\beta$-Catenin Pathway}

To further investigate TUFT1-regulated metastasis in TNBC cells, we performed Racl activity assays following manipulation of TUFT1 expression levels. This revealed that knockdown of endogenous TUFT1 decreased Rac1-GTP levels in MDA-MB231 cells $(p<0.01$, Figure $2 A$ ), whereas TUFT1 overexpression increased Rac1-GTP levels in HCC1937 cells $(p<0.05$,
Figure 2B). These data indicate that TUFT1 promotes Rac1 activation in TNBC cells.

To investigate the potential role of Racl downstream of TUFT1, endogenous Rac1-GTP was inhibited using the Rac1 inhibitor NSC23766 (29) in TUFT1 overexpression TNBC cells. We confirmed that NSC23766-mediated inhibition of Rac1 was associated with a substantial reduction in its active form, Rac1GTP (Figure 2C). The activation of Wnt/ $\beta$-catenin pathway is related to the proliferation and metastasis of $\operatorname{TNBC}(35,36)$. Interestingly, we found that $\beta$-catenin levels were significantly increased by TUFT1 overexpression in both TNBC cells $(p<$ 0.01 , Figure 2D). However, the increase in $\beta$-catenin induced by TUFT1 overexpression was significantly decreased by NSC23766 treatment in both TNBC cells, compared to the controls $(p<$ 0.01 , Figure 2D). Consistent with this, we observed that TUFT1dependent TNBC cells metastasis was reversed in cells treated with NSC23766, as assessed by both invasion and transwell assays $(p<0.05$, Figures 2E,F). In conclusion, these results suggest that Rac1 is necessary for TUFT1-dependent $\beta$-catenin activation and TNBC cells metastasis.

\section{TUFT1 Promotes the Stemness of TNBC Cells by Up-Regulating the Rac1 Signaling Pathway}

To further investigate the regulation of TNBC cell stemness by TUFT1, we once again employed the Rac1 inhibitor NSC23766 (29) to inhibit endogenous Rac1-GTP in both TUFT1 overexpression TNBC cells. We found that Nanog, Sox2, and Oct4 levels were significantly increased by TUFT1 overexpression in both TNBC cells $(p<0.05$, Figure 3A). However, the TUFT1-induced increase in Nanog, Sox2, and Oct 4 was significantly decreased by NSC 23766 treatment in both TNBC cells, compared to the corresponding controls $(p<0.05$, Figure 3A). Consistent with this, we observed that NSC23766 treatment in MDA-MD-231 cells impaired TUFT1-dependent CSC-like properties, as assessed by the sphere formation assay $(p<0.01$, Figure 3B).

\section{TUFT1 Inhibits Chemotherapy-Mediated Apoptosis in TNBC Cells by Targeting the Rac1/ $\beta$-Catenin Signaling Pathway}

ONCOMINE data showed that TUFT1 mRNA levels were significantly lower in epirubicin/docetaxel responder BC samples than epirubicin/docetaxel non-responder BC samples $(p=$ 0.031 , Figure 4A). To evaluate whether TUFT1 expression can directly contribute to resistance to chemotherapy in TNBC, we used MDA-MB-231-shTUFT1 cells (or control MDA-MB231 cells) in a xenograft tumor model. IHC staining revealed that the tumors formed by the MDA-MB-231-TUFT1-shRNA 
A

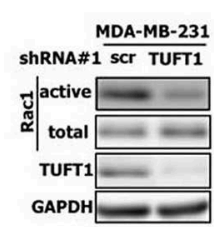

C
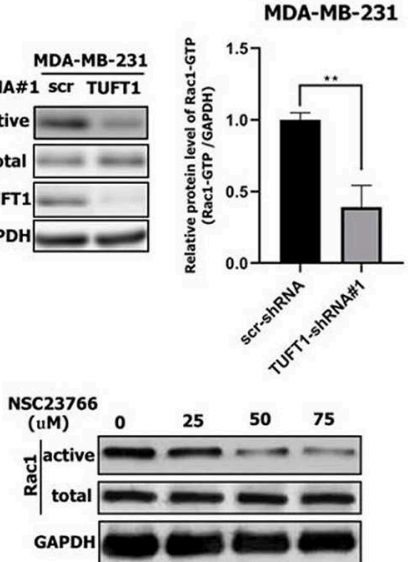

B

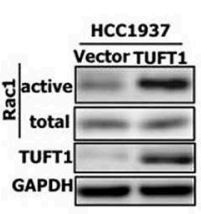

MDA-MB-231

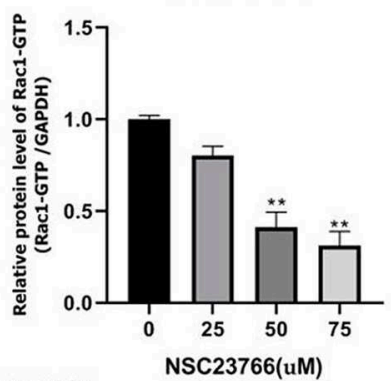

$3766(\mathrm{uM})$

D
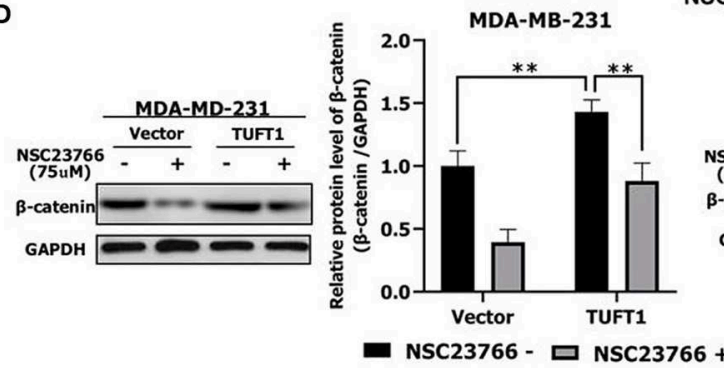

E
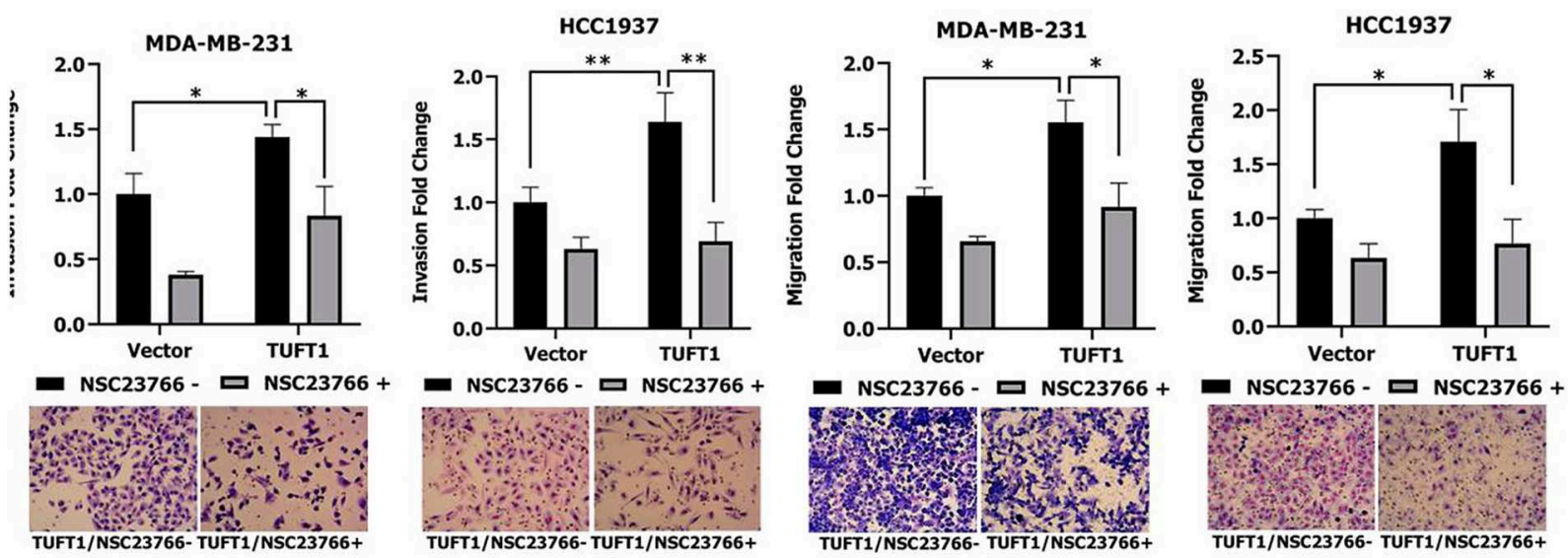

FIGURE 2 | Role of TUFT1 in TNBC migration and invasiveness by promoting the Rac1/ $\beta$-catenin signaling pathway. (A) Down-regulation of TUFT1 by shRNA dramatically decreased the protein level of Rac1-GTP in MDA-MB-231 cells $(n=3)$. (B) Overexpression of TUFT1 increased the protein level of Rac1-GTP in HCC1937 cells $(n=3)$. (C) Western blot showed effect of Rac1 inhibitor NSC23766 on Rac1-GTP in MDA-MB-231 cells $(n=3)$. (D) Down-regulation of Rac1-GTP treated with NSC23766 decreased expression of $\beta$-catenin in TUFT1-MDA-MB-231 and TUFT1-HCC1937 cells $(n=3)$. Down-regulation of Rac1-GTP treated with NSC23766 decreased cell invasiveness $(\mathbf{E})$ and migration in $\mathbf{( F )}$ in TUFT1-MDA-MB-231 and TUFT1-HCC1937 cells $(n=3)$. Results are presented as means \pm SD. The statistical significance was assessed by student's $t$-test; ${ }^{*} p<0.05,{ }^{* *} p<0.01$.

cells had lower TUFT1 expression than those formed by the control cells (Figure 4B). The size of tumors formed by TUFT1positive cells was slightly reduced by doxorubicin treatment ( $p>0.05$, Figure 4C), whereas the size of the tumors formed by
TUFT1-negative cells was significantly reduced by doxorubicin treatment $(p<0.05$, Figure 4C). These results show that the expression of TUFT1 is directly related to the increase of chemoresistance. 
A

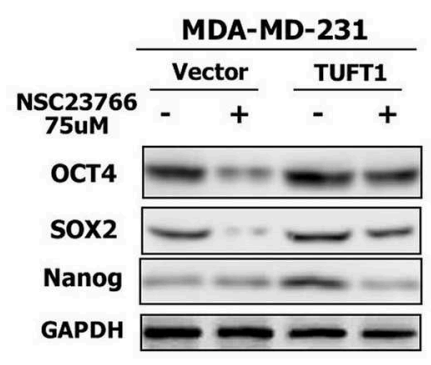

MDA-MB-231

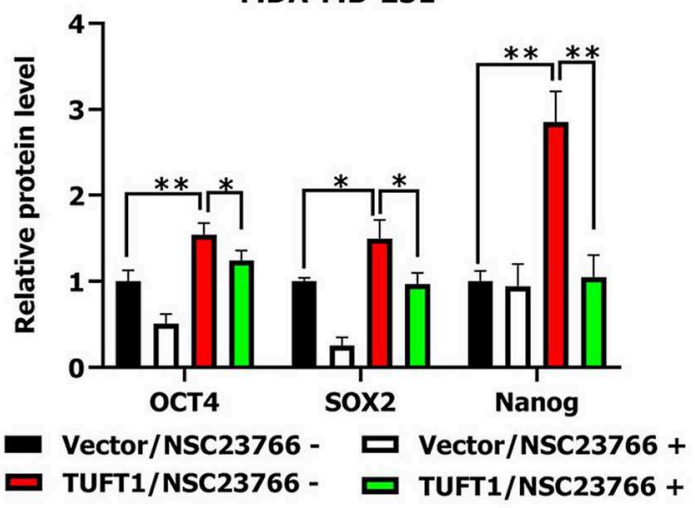

HCC1937

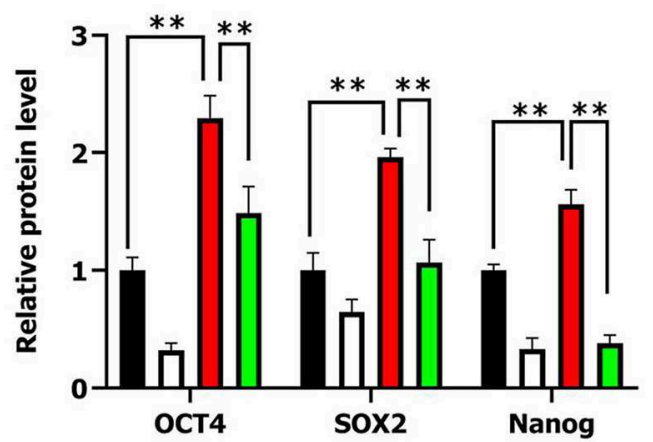

- Vector/NSC23766 - 口 Vector/NSC23766 +

口TUFT1/NSC23766 - $\square$ TUFT1/NSC23766 +

B

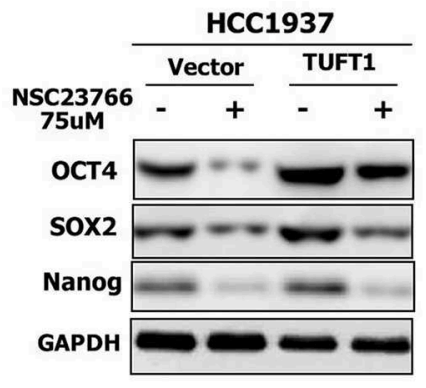

MDA-MB-231

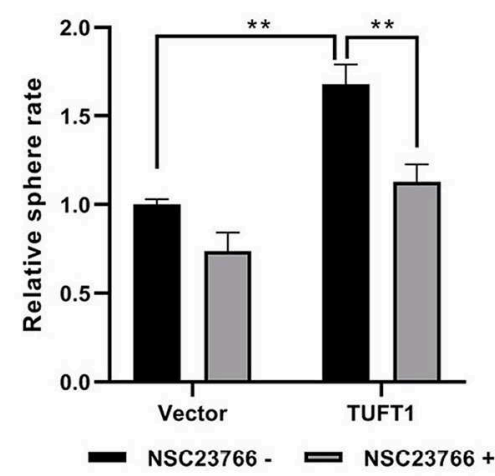

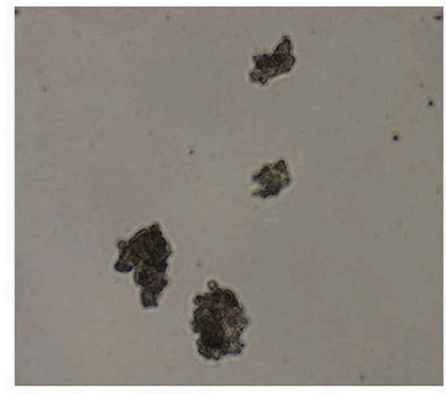

TUFT1/NSC23766-

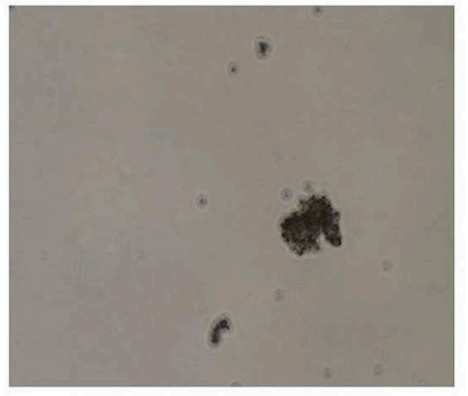

TUFT1/NSC23766+

FIGURE 3 | Role of TUFT1 in TNBC stemness by promoting the Rac1 signaling pathway. (A) Down-regulation of Rac1-GTP treated with NSC23766 decreased expression of Nanog, Sox2, and Oct4 levels in TUFT1-MDA-MB-231 and TUFT1-HCC1937 cells $(n=3)$. (B) Down-regulation of Rac1-GTP treated with NSC23766 decreased number of mammary spheres formed by TUFT1 - MDA-MB-231 cells $(n=3)$. Results are presented as means \pm SD. The statistical significance was assessed by student's $t$-test; ${ }^{\star} p<0.05,{ }^{\star \star} p<0.01$.

We next wondered whether TUFT1 confers resistance to chemotherapy in TNBC cells via the Rac1/ $\beta$-catenin signaling pathway. Treatment of TUFT1-negative MDA-MB-231 cells with doxorubicin and HCC1937 cells with taxotere induced a decrease in both Rac1-GTP and $\beta$-catenin levels in a dose-dependent manner (Figures 4D,E). The protein levels of
Rac1-GTP and $\beta$-catenin were significantly lower in TUFT1negative cells than in TUFT1-positive cells following treatment with corresponding dose of doxorubicin and taxotere $(p<$ 0.05 , Figures 4D,E). However, the level of total Racl protein was unchanged (Figures 4D,E). Furthermore, we observed a significantly higher level of apoptosis in TUFT1-negative cells 
A

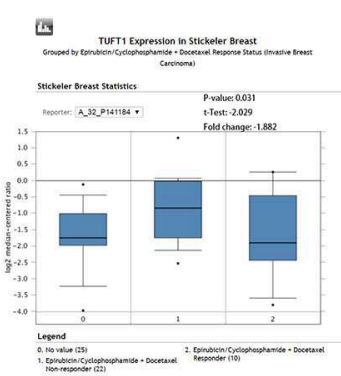

B

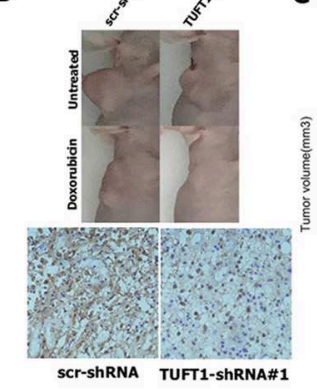

C

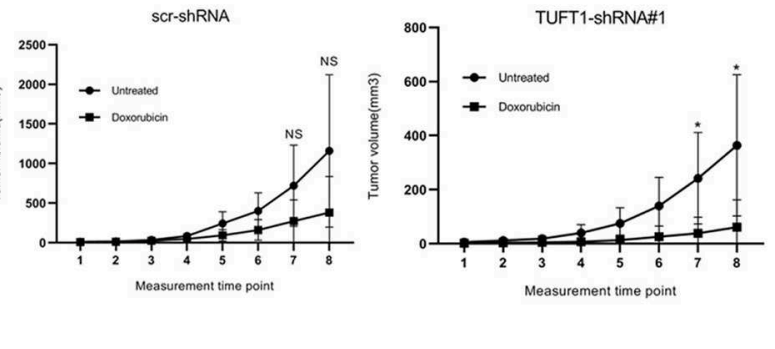

D
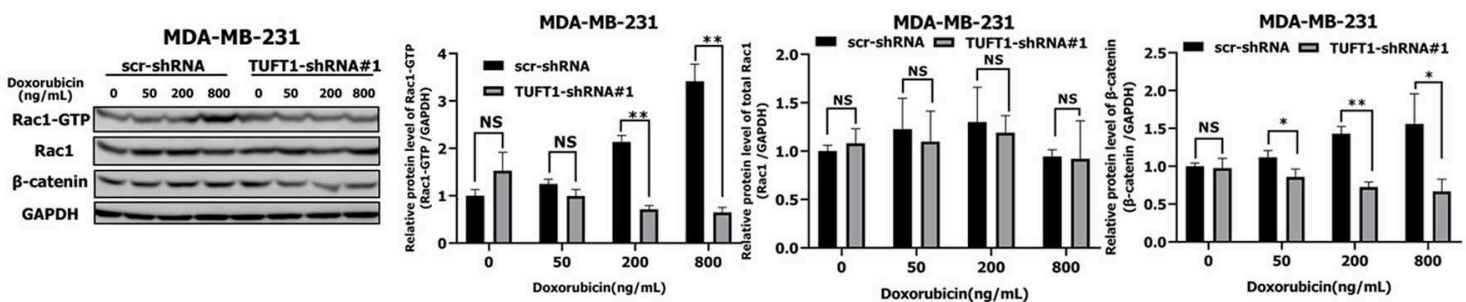

E

HCC1937

HCC1937

HCC1937

HCC1937
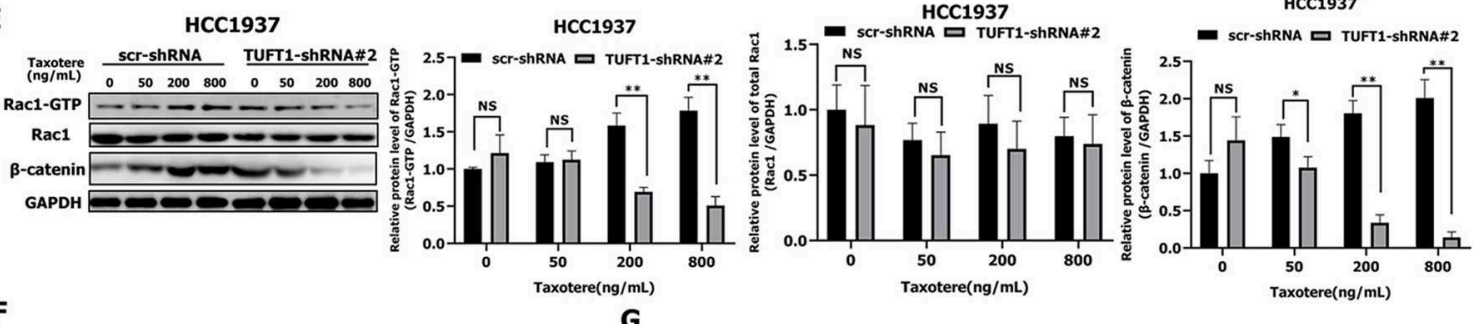

F

G
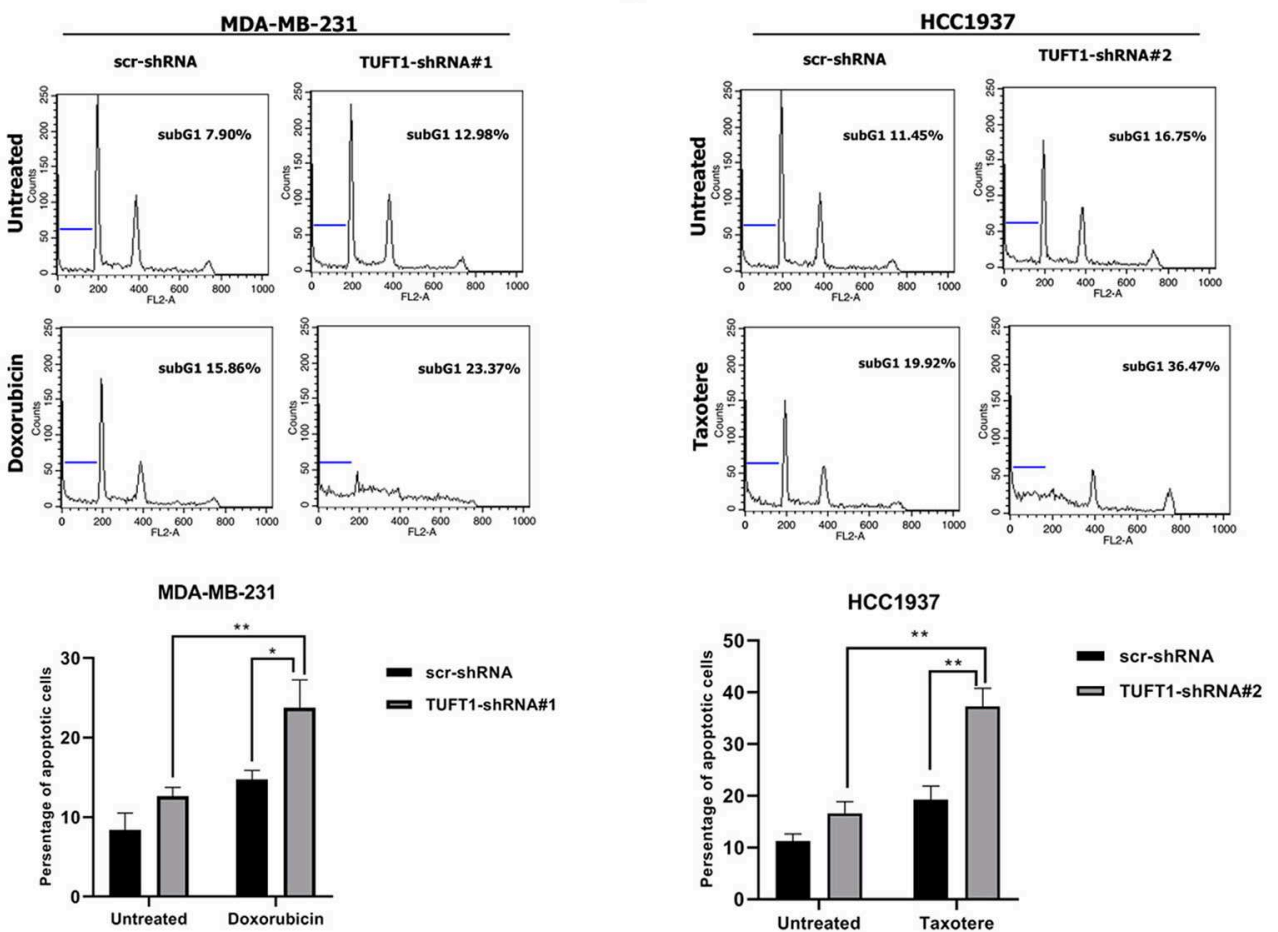

FIGURE 4 | TUFT1-knockdown TNBC cells are more sensitive to doxorubicin and taxotere. (A) TUFT1 mRNA expression was lower in epirubicin/docetaxel responder BC samples by ONCOMINE analysis. (B) scr-shRNA- and TUFT1-shRNA-MDA-MB-231 cells were injected into nude mice as described in the Materials and Methods. 
FIGURE 4 | The tumor volumes were measured following treatment with or without doxorubicin $(n=5)$. Representative images showing tumor formed in nude mice after injection with scr-shRNA- or TUFT1-shRNA cells and IHC staining of TUFT1 in tumor tissues. (C) Tumor volumes in four groups. (D,E) Western blot showing the expression levels of Rac1-GTP, Rac1 and $\beta$-catenin in scr-shRNA- and TUF1-shRNA-MDA-MB-231 cells following treatment with various doses of doxorubicin or TUFT1-shRNA-HCC1937 cells following treatment with various doses of taxotere for $24 \mathrm{~h}(n=3)$. (F,G) Apoptotic cell death was detected by PI single staining method following treatment of scr-shRNA- and TUFT1-shRNA-MDA-MB-231 cells without or with $200 \mathrm{ng} \mathrm{ml}^{-1}$ of doxorubicin or TUFT1-shRNA-HCC1937 cells without or with $200 \mathrm{ng} \mathrm{ml}^{-1}$ of taxotere for $24 \mathrm{~h}(n=3)$. Numbers in the subG1 phase (blue bar) represent the percentage of apoptosis. Results are presented as means \pm SD. The statistical significance was assessed by student's t-test; ${ }^{*} p<0.05,{ }^{\star *} p<0.01$.

A

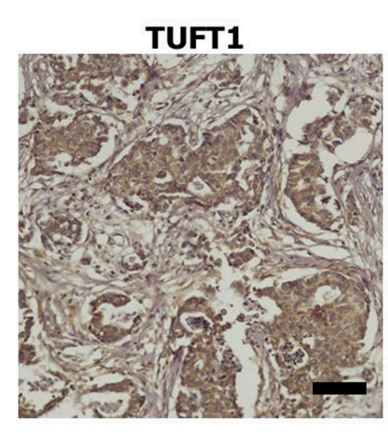

Rac1-GTP

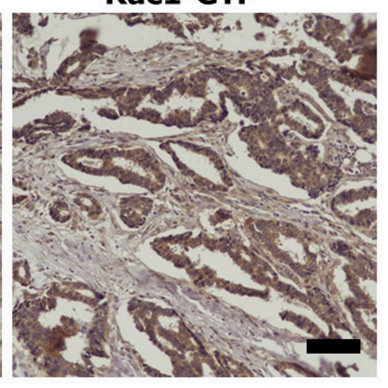

B

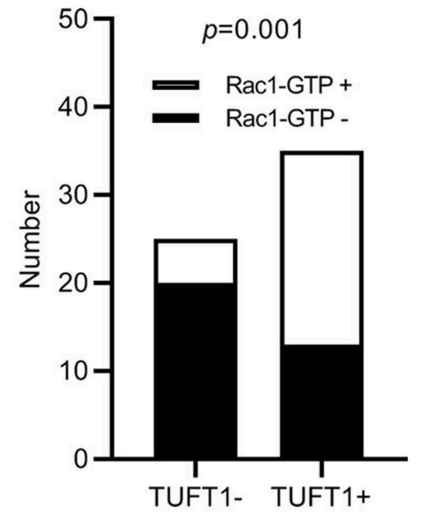

C

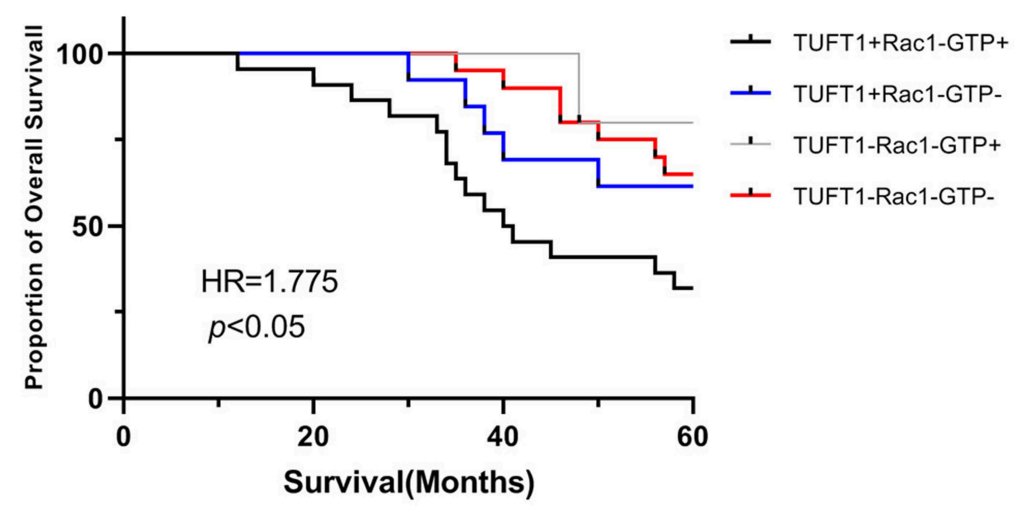

FIGURE 5 | The expression of TUFT1 and Rac1-GTP in 60 TNBC patients who had received anthracycline/taxanes chemotherapy after surgery. (A) Show the positive expression of TUFT1 and Rac1-GTP in serial sections. (B) Rac1-GTP positively correlated with TUFT1 expression in the TNBC samples. (C) Kaplan-Meier survival curves showing survival in 60 patients who received chemotherapy blotted in relation to TUFT1 and Rac1-GTP expression. Survival curves showing the poor overall survival in patients with tumors co-expressing TUFT1 and Rac1-GTP that received chemotherapy.

than in TUFT1-positive cells following treatment with $200 \mathrm{ng} / \mathrm{mL}$ doxorubicin or taxotere ( $p<0.05$, Figures $4 F, G)$. These results indicate that TUFT1 may confer resistance to chemotherapy in TNBC cells by promoting cell apoptosis via the Rac $1 / \beta$-catenin signaling pathway.

\section{TUFT1 and Rac1-GTP Expression Positively Correlate and Predict Poor Prognosis Following Treatment With Chemotherapy in TNBC}

We next studied the clinical correlation of TUFT1 and Rac1GTP using 60 TNBC specimens from patients who had received anthracycline followed by taxanes chemotherapy after surgery. Examples of positive expression of TUFT1 and Rac1-GTP in serial sections are presented in Figure 5A. The level of TUFT1 protein was positively correlated with tumor size, histological grade and axillary lymph node metastasis $(p=0.010, p=$ 0.005 , and $p=0.010$, respectively, Table 1). The level of Rac1GTP protein positively correlated with TUFT1 expression in the TNBC samples ( $p=0.001$, Table 2 ; Figure 5B). We divided the patients into four groups according to the TUFT1 and Rac1GTP expression in the TNBC samples. Our patient follow-up analysis showed that a total of 27 of 60 patients died, and the 5years overall survival rate was $55.0 \%$. Fourteen of the 22 patients with tumors co-expressing TUFT1 and Rac1-GTP were dead, 
TABLE 1 | The relationship between TUFT1 expression and the clinicopathological factors in TNBC patients who have received chemotherapy $(n=60)$.

\begin{tabular}{|c|c|c|c|c|}
\hline Variable & $n$ & TUFT1- & TUFT1 ${ }^{+}$ & $p$-variable \\
\hline Age & & & & 0.695 \\
\hline$\geq 40$ & 49 & 21 & 28 & \\
\hline$<40$ & 11 & 4 & 7 & \\
\hline Tumor size & & & & 0.010 \\
\hline $\mathrm{T} 1$ & 16 & 11 & 5 & \\
\hline T2-4 & 44 & 14 & 30 & \\
\hline Histological grades & & & & 0.005 \\
\hline ।, II & 28 & 17 & 11 & \\
\hline III & 32 & 8 & 24 & \\
\hline Lymph node metastasis & & & & 0.010 \\
\hline- & 18 & 12 & 6 & \\
\hline+ & 42 & 13 & 29 & \\
\hline
\end{tabular}

TABLE 2 | Correlations between expression of TUFT1 and Rac1-GTP.

\begin{tabular}{lcccc}
\hline Variable & $\boldsymbol{n}$ & Rac1-GTP & Rac1-GTP+ & $\boldsymbol{p}$-variable \\
\hline TUFT1 & & & & 0.001 \\
- & 25 & 20 & 5 & \\
+ & 35 & 13 & 22 & \\
\hline & & & &
\end{tabular}

and this group displayed the lowest 5 years survival than other groups (log-rank test, $p<0.05$, Hazard Ratio $=1.775,95 \% \mathrm{CI}$ of ratio $=0.986-3.195$, Figure 5C). Therefore, TUFT1 and Rac1GTP expression positively correlate and predict patient prognosis following treatment with chemotherapy in TNBC.

\section{DISCUSSION}

To our knowledge, this is the first systematic study on the functional mechanism of TUFT1 mediated metastasis and stemness in TNBC. Zhou et al. (11) reported that TUFT1 overexpression promoted the metastasis of pancreatic cancer cells, and affected the expression of a number of epithelialmesenchymal transformation-related proteins. They suggested that TUFT1 may affect HIF1 by influencing the expression of members of the Snail signaling pathway, which regulates epithelial-mesenchymal transition. Kawasak et al. (14) found that TUFT1 may be activated by the AKT/mTOR pathway to regulate tumor proliferation and metastasis. Compared to cells of other breast cancer subtypes, basal mesenchymal-like TNBC cells display increased migration, invasion, and metastatic potential (37). In this study, we found that TUFT1 promotes the metastasis of TNBC cells both in vitro and in vivo. CSCs have high tumorigenic capacity and are important features of new tumors (secondary and third foci) at locations other than those of the original tumor $(38,39)$. Here, we propose for the first time that TUFT1 can regulate the stemness of TNBC cells. TUFT1 knockdown in TNBC cells reduced the number of mammary spheres and stemness-associated molecules. These results reveal that TUFT1 may promote the metastasis of TNBC cells by upregulating their stem capacity.

Rac1, a member of the Rac subfamily of small GTPases, has its forms of active GTP-bound and inactive GDP-bound. Racl activity plays roles in the regulation of proliferation, differentiation, apoptosis, cell movement, and adhesion. Moreover, Rac1 has been shown to have an important role in tumor cell migration (40). Rac1-GTP interacts with different downstream effector molecules, thus affecting tumor invasion and metastasis (41). $\beta$-catenin, a target molecule of Rac1, is a key regulator of cell proliferation and metastasis $(42,43) . \beta$-catenin is a multi-gene nuclear transcription target. It can regulate the proliferation and metastasis of cancer cells $(44,45)$. Rac1 gene regulates $\beta$-catenin and locates its nucleus at the promoter TCF3/4 of target gene (46). Furthermore, active/inactive Rac1 state was shown to direct Rac1- $\beta$-catenin complex to the nucleus in CRC cells (47). De et al. (36) demonstrated that Rac1 was activated by cascade of $\beta$-catenin-Tiam1/vav2 as downstream target of $\mathrm{Wnt} / \beta$-catenin pathway activation during TNBC metastasis. However, our results show that TUFT1 can promote the metastasis of TNBC cells by activating Rac1 in the $\operatorname{Rac} 1 / \beta$-catenin signaling pathway, suggesting that the TUFT $1 / \mathrm{Rac} 1 / \beta$-catenin axis may regulate metastasis in TNBC. NSC23766 reduces total $\beta$-catenin in CRC cells, thus demonstrating that Rac1 regulates stemness in CRC by activating Wnt/ $\beta$-catenin signaling (29). Our study further implicates Racl and its downstream target $\beta$-catenin as critical molecules in the regulation of stemness in TNBC downstream of TUFT1. Our study identifies the TUFT1/Rac1/ $\beta$-catenin axis as a novel regulator of metastasis and stemness in TNBC. However, how TUFT1 specifically regulates Rac1 expression, in a recent study, Kawasak et al. (14) found that TUFT1 activated the mTORC1 signaling pathway by regulating the Rab GTPase, and that the interaction of TUFT1 and RabGAP1 mediated intracellular lysosome localization and vesicle transport in $\mathrm{BC}$ cells, while Rac1 is the substrate of mTOR. In addition, through high-throughput differential gene screening, TUFT1 was found to be associated with Rab5 and Rac1 (13). Rab5 is responsible for regulating the early stage of vesicle transport. Once activated, Rab5 recruits a number of interacting proteins, such as Rac1 and Tiam1, which play an important role in tumor metastasis $(48,49)$. Díaz et al. (50) found that Rab5 activation could recruit Tiam 1 around the endosome, thereby leading to the activation of Rac1. Based on this, we hypothesize that TUFT1 may initiate vesicle transport through activating Rab5, thereby affecting downstream Rac1 expression. So, regulatory processes may be complex, the relationship between TUFT1 and Rac1 needs further study.

As endocrine therapy or HER2 targeted therapy is ineffective for TNBC patients. Chemotherapy is the most effective treatment at present. In addition, more than $50 \%$ of TNBCs were resistant to adjuvant chemotherapy. Because of chemotherapeutic resistance, patients often have relapse and metastasis $(51,52)$. In 2015, experts at St. Gallen agreed to recommend anthracyclines and taxanes as the main adjuvant chemotherapeutic drugs for TNBC. However, the use of platinum antineoplastic drugs 
is still controversial $(53,54)$. Here, we demonstrated that TUFT1 knockdown can reverse doxorubicin resistance in a TNBC xenograft tumor model. Meanwhile, TUFT1 suppression conferred sensitivity to chemotherapy and increased cell apoptosis via inhibition of $\mathrm{Rac} 1 / \beta$-catenin signaling in TNBC cells. The mechanism of Racl-mediated chemoresistance has been studied in several tumors $(23,55-57)$. We have found in previous studies that TUFT1 can inhibit the apoptosis of BC cells and the activation of Caspase 3 (13). Racl can regulate the DNA damage response, drug-induced apoptosis, and tumor metastasis by activating a number of stress-activated kinases, such as JNK and p38 kinase, which can regulate the activation of Caspase $3(58,59)$. In addition, dual specificity phosphatase-1 (DUSP1) can dephosphorylate all three family members of MAPK (ERK1/2, JNK1/2, p38 MAPK), which play a negative regulatory role in MAPK signaling pathway $(60,61)$. DUSP1 mediates breast cancer proliferation and chemotherapy resistance by inhibiting JNK pre-apoptotic signaling pathway $(62,63)$. TUFT1 can regulate DUSP1 expression in our previous studies (13), therefore, we consider whether there is a link between TUFT1/Rac1 pathway and DUSP1 to regulate downstream MAPK pathways, or whether TUFT1 directly mediates DUSP1 bypass signal to regulate apoptosis and chemoresistance of BC cells. This requires further study. CSCs as a target is a promising method for reversing chemoresistance, and activated $\mathrm{Wnt} / \beta$-catenin pathway also can inhibit apoptosis of BC cells and confer the stemness of BC cells and lead to chemoresistance (64-66). Therefore, these results suggest that the TUFT1/Rac1/ $\beta$-catenin axis can at least partially inhibit TNBC cells apoptosis and then promote doxorubicin/taxotere resistance in TNBC. Moreover, TUFT1 expression positively correlates with Rac1-GTP, and co-expression of TUFT1 and Rac1-GTP predicts poor patient prognosis in TNBC following adjuvant doxorubicin/taxotere treatment. Thus, TUFT1 may be a potential novel clinical therapy target for reversing chemoresistance in TNBC.

\section{CONCLUSIONS}

In summary, we first systematic study on the functional mechanism of TUFT1 mediated metastasis, stemness and chemoresistance in TNBC. Our results find that TUFT1 can promotes the metastasis and stemness of TNBC cells via the $\mathrm{RAC} 1 / \beta$-catenin pathway, meanwhile, TUFT1 could increase TNBC resistance to chemotherapy induced by $\mathrm{RAC} 1 / \beta$-catenin

\section{REFERENCES}

1. Harbeck N, Gnant M. Breast cancer. Lancet. (2017) 389:1134-50. doi: 10.1016/S0140-6736(16)31891-8

2. Bianchini G, Balko JM, Mayer IA, Sanders ME, Gianni L. Triple-negative breast cancer: challenges and opportunities of a heterogeneous disease. Nat Rev Clin Oncol. (2016) 13:674-90. doi: 10.1038/nrclinonc.2016.66

3. Kumar P, Aggarwal R. An overview of triple-negative breast cancer. Arch Gynecol Obstetr. (2016) 293:247-69. doi: 10.1007/s00404-0 15-3859-y pathway. Therefore, our findings suggest that TUFT1 may provide a potential target for more effective treatment of TNBC. The mechanism of TUFT1 regulating Rac1 and the mechanism of TUFT1 mediating metastatic and apoptotic bypass signaling in TNBC cells need to be further explored.

\section{DATA AVAILABILITY}

The raw data supporting the conclusions of this manuscript will be made available by the authors, without undue reservation, to any qualified researcher.

\section{ETHICS STATEMENT}

This study was carried out in accordance with the recommendations of ICMJE of guidelines, Ethics Committee of Affiliated Hospital of Hebei University of Engineering with written informed consent from all subjects. All subjects gave written informed consent in accordance with the Declaration of Helsinki. The protocol was approved by the Ethics Committee of Affiliated Hospital of Hebei University of Engineering. This study was carried out in accordance with the recommendations of International Association of Veterinary Editors guidelines, Ethics Committee of Affiliated Hospital of Hebei University of Engineering. The protocol was approved by the Ethics Committee of Affiliated Hospital of Hebei University of Engineering.

\section{AUTHOR CONTRIBUTIONS}

WL and BC conceived the study and provided the project direction. WL guided and performed the experiments, analyzed the data, and wrote the manuscript until the final submission version. WL, GC, LS, YZ, and JHa completed the cell experiments. WL, GC, YD, JHe, and SS assisted in performing the animal experiments.

\section{FUNDING}

This research was supported in part by the Science and Technology Research and Development Project of Handan (Grant No. 1823208029ZC), the National Natural Science Foundation of China (Grant No. 31601142), and the Key Science and Technology Research Program of Hebei Provincial Department of Health (Grant No. 20190962). 
7. Kennecke H, Yerushalmi R, Woods R, Cheang MC, Voduc D, Speers CH, et al. Metastatic behavior of breast cancer subtypes. J Clin Oncol. (2010) 28:3271-7. doi: $10.1200 /$ JCO.2009.25.9820

8. Dent R, Trudeau M, Pritchard KI, Hanna WM, Kahn HK, Sawka CA, et al. Triple-negative breast cancer: clinical features and patterns of recurrence. Clin Cancer Res. (2007) 13:4429-34. doi: 10.1158/1078-0432.CCR-06-3045

9. Bayraktar S, Gluck S. Molecularly targeted therapies for metastatic triple-negative breast cancer. Breast Cancer Res Treat. (2013) 138:21-35. doi: 10.1007/s10549-013-2421-5

10. Deutsch D, Palmon A, Fisher LW, Kolodny N, Termine JD, Young MF. Sequencing of bovine enamelin ("tuftelin") a novel acidic enamel protein. $J$ Biol Chem. (1991) 266:16021-8.

11. Zhou B, Zhan $\mathrm{H}$, Tin L, Liu S, Xu J, Dong Y, et al. TUFT1 regulates metastasis of pancreatic cancer through HIF1-Snail pathway induced epithelial-mesenchymal transition. Cancer Lett. (2016) 382:11-20. doi: 10.1016/j.canlet.2016.08.017

12. Weiguang Liu JD, Min Zhao, Lei Zhang, Zining Jin, Bo Chen. Clinical implications of TUFT1 protein expression and correlation with RelA protein in breast cancer. Int J Clin Exp Pathol. (2017) 10:6544-51. doi: 10.1038/nrclinonc.2016.666544-6551

13. Liu W, Zhang L, Jin Z, Zhao M, Li Z, Chen G, et al. TUFT1 is expressed in breast cancer and involved in cancer cell proliferation and survival. Oncotarget. (2017) 8:74962-74. doi: 10.18632/oncotarget.20472

14. Kawasaki N, Isogaya K, Dan S, Yamori T, Takano H, Yao R, et al. TUFT1 interacts with RABGAP1 and regulates mTORC1 signaling. Cell Disc. (2018) 4:1. doi: 10.1038/s41421-017-0001-2

15. Ridley AJ. Rho GTPase signalling in cell migration. Curr Opin Cell Biol. (2015) 36:103-12. doi: 10.1016/j.ceb.2015.08.005

16. Hall A. Rho GTPases and the actin cytoskeleton. Science. (1998) 279:509-14. doi: $10.1126 /$ science. 279.5350 .509

17. Orgaz JL, Herraiz C, Sanz-Moreno V. Rho GTPases modulate malignant transformation of tumor cells. Small GTPases. (2014) 5:e29019. doi: $10.4161 /$ sgtp. 29019

18. Burbelo P, Wellstein A, Pestell RG. Altered Rho GTPase signaling pathways in breast cancer cells. Breast Cancer Res Treat. (2004) 84:43-8. doi: 10.1023/B:BREA.0000018422.02237.f9

19. Baugher PJ, Krishnamoorthy L, Price JE, Dharmawardhane SF. Rac1 and Rac3 isoform activation is involved in the invasive and metastatic phenotype of human breast cancer cells. Breast Cancer Res. (2005) 7:R965-74. doi: $10.1186 /$ bcr1329

20. Fritz G, Brachetti C, Bahlmann F, Schmidt M, Kaina B. Rho GTPases in human breast tumours: expression and mutation analyses and correlation with clinical parameters. Br J Cancer. (2002) 87:635-44. doi: 10.1038/sj.bjc. 6600510

21. Zhang B, Zhang Y, Dagher MC, Shacter E. Rho GDP dissociation inhibitor protects cancer cells against drug-induced apoptosis. Cancer Res. (2005) 65:6054-62. doi: 10.1158/0008-5472.CAN-05-0175

22. Kreger BT, Johansen ER, Cerione RA, Antonyak MA. The enrichment of survivin in exosomes from breast cancer cells treated with paclitaxel promotes cell survival and chemoresistance. Cancers. (2016) 8:111. doi: $10.3390 /$ cancers 8120111

23. Hofbauer SW, Krenn PW, Ganghammer S, Asslaber D, Pichler U, Oberascher K, et al. Tiam1/Rac1 signals contribute to the proliferation and chemoresistance, but not motility, of chronic lymphocytic leukemia cells. Blood. (2014) 123:2181-8. doi: 10.1182/blood-2013-08-523563

24. Ikram M, Lim Y, Baek SY, Jin S, Jeong YH, Kwak JY, Yoon S. Cotargeting of Tiam1/Racl and Notch ameliorates chemoresistance against doxorubicin in a biomimetic 3D lymphoma model. Oncotarget. (2018) 9:2058-75. doi: 10.18632/oncotarget.23156

25. Velaithan R, Kang J, Hirpara JL, Loh T, Goh BC, Le Bras M, et al. The small GTPase Rac1 is a novel binding partner of $\mathrm{Bcl}-2$ and stabilizes its antiapoptotic activity. Blood. (2011) 117:6214-26. doi: 10.1182/blood-2010-08-301283

26. Gangemi RM, Griffero F, Marubbi D, Perera M, Capra MC, Malatesta P, et al. SOX2 silencing in glioblastoma tumor-initiating cells causes stop of proliferation and loss of tumorigenicity. Stem Cells. (2009) 27:40-8. doi: 10.1634/stemcells.2008-0493

27. Wen K, Fu Z, Wu X, Feng J, Chen W, Qian J. Oct-4 is required for an antiapoptotic behavior of chemoresistant colorectal cancer cells enriched for cancer stem cells: effects associated with STAT3/Survivin. Cancer Lett. (2013) 333:56-65. doi: 10.1016/j.canlet.2013.01.009

28. Zhang J, Espinoza LA, Kinders RJ, Lawrence SM, Pfister TD, Zhou M, et al. NANOG modulates stemness in human colorectal cancer. Oncogene. (2013) 32:4397-405. doi: 10.1038/onc.2012.461

29. Rao J, Zhou ZH, Yang J, Shi Y, Xu SL, Wang B, et al. Semaphorin-3F suppresses the stemness of colorectal cancer cells by inactivating Rac1. Cancer Lett. (2015) 358:76-84. doi: 10.1016/j.canlet.2014.12.040

30. Ghebeh H, Al-Khaldi S, Olabi S, Al-Dhfyan A, Al-Mohanna F, Barnawi R, et al. Fascin is involved in the chemotherapeutic resistance of breast cancer cells predominantly via the PI3K/Akt pathway. Br J Cancer. (2014) 111:1552-61. doi: 10.1038/bjc.2014.453

31. Nguyen LV, Vanner R, Dirks P, Eaves CJ. Cancer stem cells: an evolving concept. Nat Rev Cancer. (2012) 12:133-43. doi: 10.1038/nrc3184

32. Shukla S, Meeran SM. Epigenetics of cancer stem cells: pathways and therapeutics. Biochim Biophys Acta. (2014) 1840:3494-502. doi: 10.1016/j.bbagen.2014.09.017

33. Yang $\mathrm{F}$, Zhang J, Yang H. OCT4, SOX2, NANOG positive expression correlates with poor differentiation, advanced disease stages, worse overall survival in HER2 ${ }^{+}$breast cancer patients. OncoTargets Ther. (2018) 11:7873-81. doi: $10.2147 /$ OTT.S173522

34. Tulsyan S, Agarwal G, Lal P, Mittal B. Significant association of combination of OCT4, NANOG, SOX2 gene polymorphisms in susceptibility and response to treatment in North Indian breast cancer patients. Cancer Chemother Pharmacol. (2014) 74:1065-78. doi: 10.1007/s00280-014-2588-4

35. Wei Z, Shaikh ZA. Cadmium stimulates metastasis-associated phenotype in triple-negative breast cancer cells through integrin and beta-catenin signaling. Toxicol Appl Pharmacol. (2017) 328:70-80. doi: 10.1016/j.taap.2017.05.017

36. De P, Carlson JH, Jepperson T, Willis S, Leyland-Jones B, Dey N. RAC1 GTPase signals Wnt-beta-catenin pathway mediated integrin-directed metastasisassociated tumor cell phenotypes in triple negative breast cancers. Oncotarget. (2017) 8:3072-103. doi: 10.18632/oncotarget.13618

37. Humphries B, Wang Z, Oom AL, Fisher T, Tan D, Cui Y, et al. MicroRNA-200b targets protein kinase Calpha and suppresses triple-negative breast cancer metastasis. Carcinogenesis. (2014) 35:2254-63. doi: 10.1093/carcin/bgul33

38. Magee JA, Piskounova E, Morrison SJ. Cancer stem cells: impact, heterogeneity, uncertainty. Cancer Cell. (2012) 21:283-96. doi: 10.1016/j.ccr.2012.03.003

39. Pang R, Law WL, Chu AC, Poon JT, Lam CS, Chow AK, et al. A subpopulation of CD26+ cancer stem cells with metastatic capacity in human colorectal cancer. Cell Stem Cell. (2010) 6:603-15. doi: 10.1016/j.stem.2010.04.001

40. Lobos-Gonzalez L, Aguilar L, Diaz J, Diaz N, Urra H, Torres VA, et al. Ecadherin determines Caveolin-1 tumor suppression or metastasis enhancing function in melanoma cells. Pigment Cell Mel Res. (2013) 26:555-70. doi: 10.1111/pcmr.12085

41. Palamidessi A, Frittoli E, Garre M, Faretta M, Mione M, Testa I, et al. Endocytic trafficking of Rac is required for the spatial restriction of signaling in cell migration. Cell. (2008) 134:135-47. doi: 10.1016/j.cell.2008.05.034

42. Hall A. The cytoskeleton and cancer. Cancer Metast Rev. (2009) 28:5-14. doi: 10.1007/s10555-008-9166-3

43. Hughes SC, Fehon RG. Understanding ERM proteins-the awesome power of genetics finally brought to bear. Curr Opin Cell Biol. (2007) 19:51-6. doi: 10.1016/j.ceb.2006.12.004

44. Goldstein B, Takeshita H, Mizumoto K, Sawa H. Wnt signals can function as positional cues in establishing cell polarity. Dev Cell. (2006) 10:391-6. doi: 10.1016/j.devcel.2005.12.016

45. Zhen T, Dai S, Li H, Yang Y, Kang L, Shi H, et al. MACC1 promotes carcinogenesis of colorectal cancer via beta-catenin signaling pathway. Oncotarget. (2014) 5:3756-69. doi: 10.18632/oncotarget.1993

46. Wu X, Tu X, Joeng KS, Hilton MJ, Williams DA, Long F. Racl activation controls nuclear localization of beta-catenin during canonical Wnt signaling. Cell. (2008) 133:340-53. doi: 10.1016/j.cell.2008.01.052

47. Buongiorno P, Pethe VV, Charames GS, Esufali S, Bapat B. Rac1 GTPase and the Rac1 exchange factor Tiam1 associate with Wnt-responsive promoters to enhance beta-catenin/TCF-dependent transcription in colorectal cancer cells. Mol Cancer. (2008) 7:73. doi: 10.1186/1476-4598-7-73

48. Teske C, Schweitzer C, Palamidessi A, Aust DE, Scita G, Weitz J, et al. Modulation of RAB5A early endosome trafficking in response to KRas 
mediated macropinocytic fluxes in pancreatic cancer cells. Biochem Biophy Res Comm. (2017) 493:528-33. doi: 10.1016/j.bbrc.2017.08.157

49. Kalin S, Hirschmann DT, Buser DP, Spiess M. Rabaptin5 is recruited to endosomes by Rab4 and Rabex 5 to regulate endosome maturation. J Cell Sci. (2015) 128:4126-37. doi: 10.1242/jcs.174664

50. Diaz J, Mendoza P, Ortiz R, Diaz N, Leyton L, Stupack D, et al. Rab5 is required in metastatic cancer cells for Caveolin-1-enhanced Racl activation, migration and invasion. J Cell Sci. (2014) 127:2401-6. doi: 10.1242/jcs.141689

51. Longley DB, Johnston PG. Molecular mechanisms of drug resistance. J Pathol. (2005) 205:275-92. doi: 10.1002/path.1706

52. Shen T, Zhang K, Siegal GP, Wei S. Prognostic value of E-cadherin and betacatenin in triple-negative breast cancer. Am J Clin Pathol. (2016) 146:603-10. doi: 10.1093/ajcp/aqw183

53. Hong J, Chen XS, Wu JY, Huang O, Zhu L, He JR, et al. [Analysis of the factors influencing adjuvant chemotherapy decisions for triple negative breast cancer]. Zhonghua zhong liu za zhi. (2017) 39:39-43. doi: 10.3760/cma.j.issn.0253-3766.2017.01.008

54. Prat A, Pineda E, Adamo B, Galvan P, Fernandez A, Gaba L, et al. Clinical implications of the intrinsic molecular subtypes of breast cancer. Breast. (2015) 2 (24 Suppl):S26-35. doi: 10.1016/j.breast.2015.07.008

55. Skvortsov S, Dudas J, Eichberger P, Witsch-Baumgartner M, Loeffler-Ragg J, Pritz C, et al. Racl as a potential therapeutic target for chemo-radioresistant head and neck squamous cell carcinomas (HNSCC). Br J Cancer. (2014) 110:2677-87. doi: 10.1038/bjc.2014.221

56. Yoon C, Cho SJ, Chang KK, Park DJ, Ryeom SW, Yoon SS. Role of Rac1 pathway in epithelial-to-mesenchymal transition and cancer stem-like cell phenotypes in gastric adenocarcinoma. Mol Cancer Res. (2017) 15:1106-16. doi: 10.1158/1541-7786.MCR-17-0053

57. Chen MJ, Wu DW, Wang YC, Chen CY, Lee H. PAK1 confers chemoresistance and poor outcome in non-small cell lung cancer via beta-catenin-mediated stemness. Scient Rep. (2016) 6:34933. doi: 10.1038/srep38463

58. Fritz G, Kaina B. Rac1 GTPase, a multifunctional player in the regulation of genotoxic stress response. Cell Cycle. (2013) 12:2521-2. doi: 10.4161/cc.25807

59. Fritz G, Henninger C. Rho GTPases: novel players in the regulation of the DNA damage response? Biomolecules. (2015) 5:2417-34. doi: 10.3390/biom5042417
60. Wu GS. Role of mitogen-activated protein kinase phosphatases (MKPs) in cancer. Cancer Metast Rev. (2007) 26:579-85. doi: 10.1007/s10555-007-9079-6

61. Hou MF, Chang CW, Chen FM, Wang SN, Yang SF, Chen PH, et al. Decreased total MKP-1 protein levels predict poor prognosis in breast cancer. World $J$ Surg. (2012) 36:1922-32. doi: 10.1007/s00268-012-1608-y

62. Wang HY, Cheng Z, Malbon CC. Overexpression of mitogen-activated protein kinase phosphatases MKP1, MKP2 in human breast cancer. Cancer Lett. (2003) 191:229-37. doi: 10.1016/S0304-3835(02)00612-2

63. Rincon R, Zazo S, Chamizo C, Manso R, Gonzalez-Alonso P, MartinAparicio E, et al. c-Jun N-terminal kinase inactivation by mitogenactivated protein kinase phosphatase 1 determines resistance to taxanes and anthracyclines in breast cancer. Mol Cancer Therap. (2016) 15:2780-90. doi: 10.1158/1535-7163.MCT-15-0920

64. Zhang L, Wang H, Li C, Zhao Y, Wu L, Du X, et al. VEGF-A/neuropilin 1 pathway confers cancer stemness via activating wnt/beta-catenin axis in breast cancer cells. Cell Physiol Biochem. (2017) 44:1251-62. doi: 10.1159/000485455

65. Cheng S, Huang Y, Lou C, He Y, Zhang Y, Zhang Q. FSTL1 enhances chemoresistance and maintains stemness in breast cancer cells via integrin beta3/Wnt signaling under miR-137 regulation. Cancer Biol Ther. (2019) 20:328-37. doi: 10.1080/15384047.2018.1529101

66. Mu J, Hui T, Shao B, Li L, Du Z, Lu L, et al. Dickkopf-related protein 2 induces G0/G1 arrest and apoptosis through suppressing Wnt/beta-catenin signaling and is frequently methylated in breast cancer. Oncotarget. (2017) 8:39443-59. doi: 10.18632 /oncotarget.17055

Conflict of Interest Statement: The authors declare that the research was conducted in the absence of any commercial or financial relationships that could be construed as a potential conflict of interest.

Copyright (ङ 2019 Liu, Chen, Sun, Zhang, Han, Dai, He, Shi and Chen. This is an open-access article distributed under the terms of the Creative Commons Attribution License (CC BY). The use, distribution or reproduction in other forums is permitted, provided the original author(s) and the copyright owner(s) are credited and that the original publication in this journal is cited, in accordance with accepted academic practice. No use, distribution or reproduction is permitted which does not comply with these terms. 